BULLETIN Bulletin hispanique

HISPANIQUE Université Michel de Montaigne Bordeaux

$112-2$ | 2010

Varia

\title{
Comprendre Góngora
}

Presses universitaires du Mirail, Toulouse, 2009

Jacques Issorel

\section{CpenEdition}

Journals

Édition électronique

URL : http://journals.openedition.org/bulletinhispanique/1291

DOI : 10.4000/bulletinhispanique.1291

ISSN : $1775-3821$

Éditeur

Presses universitaires de Bordeaux

\section{Édition imprimée}

Date de publication : 31 décembre 2010

Pagination : 849-852

ISBN : 978-2-86781-709-0

ISSN : 0007-4640

Référence électronique

Jacques Issorel, « Comprendre Góngora », Bulletin hispanique [En ligne], 112-2 | 2010, mis en ligne le 19 janvier 2013, consulté le 23 septembre 2020. URL : http://journals.openedition.org/bulletinhispanique/ 1291 ; DOI : https://doi.org/10.4000/bulletinhispanique.1291 
grâce à son travail la langue espagnole avait atteint "la perfección y alteza de la latina" (p. 16).

À plusieurs reprises enfin, Carreira souligne la musicalité de la poésie gongorine et opère un rapprochement entre le "sistema de leyes [musicales]" des vers du poète et celui qui préside aux compositions de Schubert et de Mahler (p. 16). Une "Bibliografía selecta ", et néanmoins riche (p. 35-65), et un fort utile "Índice de notas" (p. 667-692) complètent ce bel ouvrage agrémenté de neuf illustrations. Judicieusement choisie, la photo de couverture renvoie aux vers 49-50 de la Première Solitude: "Riscos que aun igualara mal volando / veloz, intrépida ala... ( p. 415).

Jacques IsSOREL

Comprendre Góngora. Robert Jammes (trad. et présentation). - Toulouse, Presses universitaires du Mirail, 2009, XV + 357 p. (Anejos de Criticón, 18).

Ce superbe ouvrage se présente sous un format oblong $(17,5 \times 24 \mathrm{~cm})$ tout à fait adapté à l'édition bilingue de textes poétiques. La couverture illustrée, la qualité du papier, la netteté de l'impression, tout concourt au plaisir du lecteur. Les 114 poèmes choisis par Robert Jammes sont imprimés en gras et leur traduction en maigre. Outre le souci de clarté et de confort du lecteur, cette différence traduit visuellement les réserves exprimées par l'auteur dans sa préface : "Rompant avec les habitudes, écrit-il, la présente anthologie bilingue ne propose pas des traductions "avec le texte de Góngora en regard", mais un choix de textes de Góngora avec une traduction en marge " (p. XIII). Dans la notice d'introduction aux Soledades, après avoir expliqué que traduire cette œuvre majeure est une entreprise désespérée, il définit modestement son texte comme un simple " marchepied [...] pour prendre possession des Soledades - en espagnol» (p. 220). La lecture concomitante des poèmes et des traductions révèle que le traducteur n'a pas dérogé à son intention de "docile exactitude " (p. XIII). Autrement dit, il cherche non pas à briller mais à aider le lecteur à découvrir dans tout leur éclat les "trésors de la forteresse " gongorine (ibid.). Il y réussit d'autant mieux qu'il conserve la prosodie des vers de Góngora en traduisant en heptasyllabes romances et décimas, en pentasyllabes romancillos et letrillas, et en décasyllabes les hendécasyllabes. 
L'anthologie proprement dite est précédée d'une préface, d'une introduction, sur laquelle nous allons revenir, d'une brève bibliographie (p. 31-33) et d'une "Note critique ». Elle est suivie de trois appendices et d'un riche index des notes (p. 341-352). Chaque poème est tantôt précédé, tantôt suivi, d'une très utile notice et fait l'objet de notes nombreuses et " nécessaires pour éclairer les difficultés qu'une pure traduction se doit de laisser en l'état " (p. XIV). L'ouvrage répond donc bien au projet énoncé par le titre : "Comprendre Góngora ". Nul doute que la substance même de cette formule a été inspirée à l'auteur par un illustre prédécesseur en matière d'exégèse gongorine, Federico García Lorca, dont il cite dans sa préface la fameuse affirmation : "C'est un problème de compréhension : Góngora, il ne faut pas le lire, mais l'étudier " (ibid.).

L'introduction (p. 1-29) s'intitule : "Vie et œuvre de Góngora. 15611627 " et se divise en neuf parties. Elle dessine avec précision et détails le parcours du poète : sa naissance et son enfance à Cordoue où, alors qu'il n'est encore qu'un jeune garçon, son destin de futur racionero est déjà tracé. Le voilà donc en 1576 étudiant en Droit canon à Salamanque où il écrit ses premières poésies. Devenu racionero à son retour à Cordoue (1585), il jouit désormais d'une situation financière enviable et partage son temps entre ses obligations ecclésiastiques, de nombreux voyages et, bien sûr, la poésie. Entre 1610 et 1614, il écrit trois grandes œuvres : la comedia Las firmezas de Isabela, la Fábula de Polifemo y Galatea et les deux Soledades, cependant son désir d'obtenir à la Cour des commanderies pour ses neveux et pour lui la chantrerie de la cathédrale de Cordoue le pousse à partir à Madrid, où il tombe dans ce que Jammes appelle "Le piège de la Cour. 1617-1626 " ( $8^{e}$ partie de l'introduction). Il n'en reviendra, désabusé, malade, ruiné, qu'en 1626 pour mourir en 1627 dans sa chère ville de Cordoue. Intitulée "Controverses posthumes (1627-1927) ", la dernière partie de l'introduction relate les heurs et malheurs qu'a connus l'œuvre de Góngora pendant trois siècles : la saisie de l'édition des Obras en verso del Homero español (édition de Vicuña) à la suite des rapports inquisitoriaux du mercedario Hernando Horio et du P. Juan de Pineda ; la publication en 1633 d'une autre édition, celle de Gonzalo de Hoces y Córdoba, "vulgate des poésies de Góngora pendant près de trois siècles» (p. 27), qui bénéficia selon toute vraisemblance de la protection du Comte Duc d'Olivarès, lequel eut le privilège de se voir offrir par Antonio Chacón les œuvres du poète calligraphiées sur vélin et réunies par lui en "trois luxueux volumes" (ibid.). C'est dans ce même manuscrit, édité en 1921 par Foulché-Delbosc, que García Lorca et ses amis découvriront la poésie de Góngora, dont ils célèbreront brillamment le tricentenaire en 1927. 
Tout au long de son introduction, Robert Jammes fait de constants renvois aux poèmes de l'anthologie (et même à d'autres que l'on trouvera dans l'édition d'Antonio Carreira des Obras completas citée dans le compte rendu précédent). De 1580 ("La más bella niña») à 1626 ("Doña Menga, ¿de qué te ríes?"), on suit pas à pas, comme dans l'anthologie de Carreira, le poète et l'évolution de son œuvre. Il n'est pas possible dans le bref espace d'une recension de décrire toute la thématique des poèmes de l'anthologie. Bornonsnous à en signaler les principaux aspects : l'amour triomphant ("Romance de Angélica y Medoro") et aussi l'amour frustré (" iQué de invidiosos montes levantados»), la satire sociale ("Que pida a un galán Minguilla») et celles que lui inspirent "la poca limpieza y la vanidad de las mujeres de Valladolid" où le duc de Lerma vient de transférer la Cour (1603) ; son désabusement après l'échec du procès engagé par sa sœur à Madrid (" $i$ Mal haya el que en señores idolatra ") et, dans ces mêmes tercets et ailleurs ("Andeme yo caliente "), son aspiration à une vie simple et provinciale. Ce même idéal de vie est aussi celui qu'exaltent les Solitudes. On rencontre également dans les poèmes le Góngora joueur ("Marco de plata excelente ») et le voyageur qui salue d'un poème chacune des villes et des régions où le conduisent sa mule et les missions du chapitre: Pampelune, Salamanque, Cuenca, Alcobendas, Lepe, Grenade, Tolède, Palencia. Jammes a aussi retenu deux poèmes où, féministe avant la lettre, don Luis " proclame (en 1621...) le droit de la femme au bonheur » (p. 314) : "Guarda corderos, zagala » et «Que se nos va la pascua, mozas". À la gravité des deux beaux sonnets "En este occidental, en este, oh Licio " et "Menos solicitó veloz saeta ", écrits en 1623 par un poète courtisan en proie à la maladie et accablé de graves soucis financiers, répondent, en 1624 et 1626, des textes pleins de malice et d'humour tels que "Con Marfisa en la estacada " et " Doña Menga... " cité plus haut. L'humour est, du reste, présent sans cesse dans la poésie de Góngora, et Jammes, par les choix qu’il opère, en présente les diverses facettes : la satire, le badinage, l'irrévérence, le burlesque, les grivoiseries.

De l'humour on en trouve aussi dans le premier appendice puisqu'il s'agit de la réponse que fit le poète aux reproches que lui avait adressés l'évêque Pacheco. La liste des charges épiscopales et la réponse sont ici transcrites et traduites intégralement. Le deuxième appendice est la traduction d'un extrait du rapport rédigé par le père Juan de Pineda à la demande de l'Inquisition et le troisième une lettre de don Luis à Juan de Villegas (1614), traduite elle aussi.

Robert Jammes indique en note dans sa bibliographie que l'anthologie d'Antonio Carreira lui est parvenue au moment où lui-même renvoyait à l'imprimeur les épreuves de la sienne. "Cette nouvelle anthologie, écrit-il, 
est une contribution de première importance aux études gongorines " ( $p$. 32). Aussi nous a-t-il semblé intéressant d'effectuer un rapide pointage : 86 textes figurent dans les deux anthologies, 114 se trouvent seulement dans celle de Carreira et 30 seulement dans celle de Jammes. C'est dire que ces deux ouvrages, d'une rigueur philologique parfaite, sont complémentaires. Outre un très large éventail de poèmes, ils offrent dans les centaines de notes et de notices qui accompagnent les textes une mine de renseignements de tous ordres non seulement sur la poésie de Luis de Góngora mais aussi sur la langue, la société et les mœurs du Siècle d'Or.

Jacques IsSOREL

Aurora Egido, El Barroco de los modernos. Despuntes y pespuntes. - Valladolid, Cátedra Miguel Delibes, 2009, 292 p.

El análisis de los problemas sobre recepción, canon y conformación de una tradición literaria se enriquece ahora, y mucho, con el Barroco de los modernos. Despuntes y pespuntes de Aurora Egido. El libro es el resultado de ordenar y disponer editorialmente el trabajo preparado por la autora para participar en un curso de doctorado en el Graduate Center de la Universidad de Nueva York (CUNY), que versó sobre el modo en que los principales escritores e intelectuales hispanos de inicios del XX leyeron lo barroco antes de que tuviera lugar el homenaje a Góngora de 1927. La indagación en estas múltiples lecturas permite a Egido a explicar cómo hicieron suyo lo barroco, de acuerdo a distintos y particulares condicionantes, y cómo lo proyectaron, en lo sucesivo, hacia los lectores futuros. Estructurado en diez capítulos, el libro traza un sólido itinerario intelectual y metodológico en el que se va desgranando la consideración que los autores del XVII tenían de las innovaciones que estaban modificando el sistema de la literatura en su tiempo, así como la manera en que los modernos autores de principios del $\mathrm{XX}$ entendieron lo barroco y trataron de explicarlo, con soluciones de muy distinta índole.

Se abre el libro con unas consideraciones previas sobre lo barroco y sobre la manera en que dicho concepto se puede revelar operativo y fructífero para un estudio cabal de las relaciones entre el XVII y el XX. Conforme a ello, plantea Egido la necesidad metodológica de rebasar el estudio de las formas e indagar en el contexto en el que estas se crean, aplicando un itinerario crítico de doble sentido que permita llevar el análisis del XVII hasta el XX, momento que en «al inventarse el término historiográfico y crítico, la propia 